\title{
Instructors' Usage and Perceptions of Mobile Devices and Applications
}

\author{
Asaad Alzayed \\ Computers \& Info. \\ Systems Department \\ Public Authority for \\ Applied Edu. \& Training \\ (PAAET), Kuwait
}

\author{
Bander Alraqqas \\ Computers \& Info. \\ Systems Department \\ Public Authority for \\ Applied Edu. \& Training \\ (PAAET), Kuwait
}

\author{
Rana Al-Hajri \\ Computer Science \\ Department \\ Public Authority for \\ Applied Edu. \& Training \\ (PAAET), Kuwait
}

\author{
Yousef Alkhawari \\ Computers \& Info. \\ Systems Department \\ Public Authority for \\ Applied Edu. \& Training \\ (PAAET), Kuwait
}

\begin{abstract}
Mobile technology is becoming increasingly prevalent in Higher Educational Institutions, and accordingly, educators must embrace and capitalize on the use of this technology to focus on integrated student services, and to enhance knowledge sharing activities in and off campus. This study investigated instructors' usage and perceptions of mobile devices, its functions, native capabilities, and applications. A sample of 48 instructors were involved in this investigation at the college of Business Studies (CBS), a HE institution in Kuwait. The aim of this study is to understand instructors' habits of the use of mobile capabilities and functions, as well as a common use of social media applications. The finding indicated instructors' frequent use of most of mobile functions, as well as the frequent use of social media applications such as twitter, YouTube, Instagram, and Snap Chat. This will guide the developers of mobile applications for CBS, and help them help to effectively utilize mobile capabilities, functions, and applications.
\end{abstract}

\section{General Terms}

Mobile Learning, Higher Education.

\section{Keywords}

Mobile technology, Mobile usage, Mobile Functions.

\section{INTRODUCTION}

The ubiquity of mobile devices, in combination with the students becoming "digitally oriented" played important role in transforming the educational landscape and bringing a host of new benefits to higher education. The expanding capabilities of mobile devices and applications are increasingly becoming prevalent. Mobile devices and applications have a great role in enhancing knowledge sharing activities among academicians and students, and help in creating new ways to connect with their campuses, course materials, students' records, and their colleagues [1]. The ubiquity of mobile devices and mobile unique capabilities which includes connectivity, portability, GPS, and cameras, have great potential to enrich the teaching experience [2]. Plenty of mobile features such as GPS, file storage, cameras, video recorder and browsing, made academicians see mobile phone technologies important tool when it comes to managing the teaching tasks [3]. As the population of campuses expands, so does the improvement of mobile technologies, Higher Education Institutions utilize mobile technologies with interesting features like camera, video, GPS, memory, MP3 player, by allowing studying and collaboration anytime anywhere $[4,5]$.

There are social and cultural implications when integrating mobile technology into any learning settings. Baker et al. (2007) gave an example of Saudi Arabia a country with cultural traditions relating to gender. They stated that the gender segregation in the Saudi educational system, have a significant impact on the attitudes and perceptions towards the use of mobile technology in learning [6]. The Kuwaiti, as an Arab culture, can dictate the use of mobile devices and applications. Like other Arab countries, the traditional culture of Kuwait greatly affects the attitudes and behaviors of its People. In Kuwait, the culture, besides security reasons, inhabits female instructors from disclosing contact information.

Kuwait has experienced strong growth in mobile penetration [7]. The high mobile phone availability among people in Kuwait is important factor that motivated the researchers to conduct this study. This Study explores the use and perceptions of mobile native functions, capabilities, and applications among instructors, at the College of Business Studies (CBS), in Kuwait, with over 500 instructors at the college and more than 8 thousand students. A sample of 48 instructors were involved in this investigation at the college of Business Studies (CBS), a HE institution in Kuwait. The aim of this study is to understand instructors' habits of the use of mobile capabilities and functions, as well as a common use of social media applications.

The rest of this article is organized as follows: Section 2 highlights some related studies, and section 3 explains the methodology used for this study. Section 4 presents results and findings, while section 5 concludes the study and suggests future directions.

\section{RELATED STUDIES}

There are many theoretical studies concerning mobile services, functions, and applications, a significant number of research investigated users' preferences and usage [5, 3]. The vast majority of these studies indicated a growing importance of mobile devices in everyday life and pointed at the increased usage of new capabilities and functions $[8,9,10]$.

According to studies performed by [4], mobile technologies could be used for many applications for academicians and students both inside and outside Higher Education Institutions (HEI). The results of studies conducted by $[11,12]$ mobile technologies allowed users to conduct 9 activities in $\mathrm{HE}$ institutions such as: sending photos/videos to colleagues, using mobile as audio player, accessing information or services on the web, making video calls, taking photos, or recording movies, sending, or receiving email, using the mobile as personal organizer, sending or receiving SMS, and calling colleagues or others. In addition, [5] explored student and instructor perceptions of personal mobile device usage for appropriate practices at a Brazilian higher education institution. The study also investigated and documented significant differences in perceptions, and found relationships between perceptions and demographic data [5]. 
Moreover, the study of [13] reported faculty perceptions regarding students' use of personal technology in the classroom. The findings indicated that some faculty ban it, some ignore it, and some use it to enhance the classroom experience. Similarly, [14] conducted a study to examined teacher educators' attitudes towards the use of mobile technology in classes, and their reactions to its use. The finding show that instructors perceive the benefits of using mobile technology in their classes as outweighing the disadvantages. There is no doubt that instructors' IT knowledge will support the proper use and the utilization of mobile technology. Instructors' attitude and lack of prior knowledge of IT use are major factors that affect the acceptance of this technology [15].

Another study was conducted by [16] on 1095 instructors from two states in the south eastern United States. The study focused on instructors' age as it relates to the relationship between the type of mobile phone they owned, their support for the use of mobile phones in the classroom, their perceptions of the benefits of mobile features and functions. The results indicated that instructors' age matters. No significant differences were found for instructors who were less than 32 and the ones who were 33-49 years, however, significant differences were found for instructors over 50 years. Older instructors were less likely to own mobile devices, were less supportive on all items, and were less enthusiastic about the mobile functions and capabilities.

\section{METHODOLOGY}

The sample of this study were 48 instructors, 18 males and 30 females from the College of Business Studies (CBS) in Kuwait HE. The sample involves a wide range of instructors from different fields and levels of study. Table (1) presents the study sample according to demographic variables.

A survey was an appropriate research tool for this study. An online questionnaire was developed for this investigation, and adapted from several previous studies $[17,5,18,10]$. The questionnaire is consisted of 3 parts. Part 1 collects demographic data, part 2 of the questionnaire investigates the use of mobile native functions and capabilities, while Part 3 examines the frequent use of the common social media applications. An online questionnaire was distributed to instructors, to understand their use of mobile device native capabilities and applications.

Data was collected from the online questionnaire and analyzed by using SPSS. Percentages, Mean, Standard Deviations (SD), were calculated. The mean is the average of instructors' choices, while standard deviation provides some idea about the distribution of instructors' scores around the mean (average). The smaller the standard deviation, the narrower the range between the lowest and highest scores [19]. An independentsample t-test was also used to assess the differences observed between means in two unrelated groups, and to determine whether there is a statistically significant difference between variables of our collected data based on instructors' gender. A significance level (sig.) of 0.05 was adopted.

\section{RESULTS \& FINDINGS}

This section presents instructors' demographic data; Instructors' use of mobile native functions; and instructors' frequent use of social media applications.

\subsection{Instructors' Demographics}

Table (1) shows that most of the instructors (48 instructors) are female $(62 \%),(94 \%)$ of them are 25 years and older. In addition, Table (1) shows that the majority of the instructors $(68 \%)$ are 'Always' using their mobile devices.

Table 1. Instructors' Demographic Data

\begin{tabular}{|c|c|c|}
\hline \multirow{2}{*}{ Gender } & Male & $38 \%$ \\
\cline { 2 - 3 } Age & Female & $62 \%$ \\
\hline \multirow{2}{*}{$\begin{array}{c}\text { How often do } \\
\text { you use your } \\
\text { mobile } \\
\text { phone }\end{array}$} & Less than 24 & $6 \%$ \\
\cline { 2 - 3 } & Always (More than 3 hours a day) & $64 \%$ \\
\cline { 2 - 3 } & Sometimes (1- 3 hours a day) & $19 \%$ \\
\cline { 2 - 3 } & Seldom (Less than 1 hour a day) & $13 \%$ \\
\hline
\end{tabular}

\subsection{Use of Mobile Native Functions and Capabilities}

Regarding instructors' use of mobile functions and capabilities, Table (2), and Figure (1) show the percentage of instructors' use of mobile native functions and applications. For example: Alarm and clock is used by (94\%); Camera (88\%); Social media (88\%); WhatsApp (82\%); Browsing (82\%); Albums (75\%); Map, SMS/MMS, and Sound (69\%); games (38\%); etc. In addition, the majority of the instructors (87\%) use mobiles for learning and knowledge acquisition. This is of note that instructors are using mobile phones to support teaching and learning processes. Based on instructors' responses to questions 1 to 14, as shown in Table (2), instructors heavily use mobile native functions, and are able to use their mobile phone as a tool to gain knowledge and information online. Table (2) also documents instructors' familiarity with using different applications on their mobile devices. It shows that instructors are accustomed to mobile functions and applications, including camera and albums, messaging, calendar and clock, games, maps, email, and social media. These findings are consistent with [10, 20,4].

T-tests, Mean, and SD were performed as shown in Table (2). Significant differences were found between male and female instructors in using mobile functions such as "Call", "SMS", "Calendar" "Camera", "Alarm/Clock", "Browsing the Web", "Sending Email", "Maps", And "Photo and Video Album", "social Networking", and "e-learning". Female instructors appear to be more active than males in using mobile functions, except for Maps, male instructors use Maps more than female instructors. 
Table 2. Instructors' Use of Mobile Functions and Applications

\begin{tabular}{|c|c|c|c|c|c|c|c|c|}
\hline & $\begin{array}{r}\text { Mobile Native Fu } \\
\text { applicatic }\end{array}$ & is and & Yes & No & I don't Know it & Mean & SD & Sig. \\
\hline \multirow{2}{*}{1} & \multirow{2}{*}{ Call } & Male & $38 \%$ & $0 \%$ & $0 \%$ & 3.00 & .000 & \multirow{2}{*}{.000} \\
\hline & & Female & $44 \%$ & $6 \%$ & $12 \%$ & 2.50 & .820 & \\
\hline \multirow{2}{*}{2} & \multirow{2}{*}{ SMS/MMS } & Male & $31 \%$ & $6 \%$ & $0 \%$ & 2.83 & .383 & \multirow{2}{*}{.000} \\
\hline & & Female & $38 \%$ & $25 \%$ & $0 \%$ & 2.60 & .498 & \\
\hline \multirow{2}{*}{3} & \multirow{2}{*}{ WhatsApp } & Male & $32 \%$ & $0 \%$ & $6 \%$ & 2.67 & .767 & \multirow{2}{*}{.586} \\
\hline & & Female & $50 \%$ & $6 \%$ & $6 \%$ & 2.70 & .651 & \\
\hline \multirow{2}{*}{4} & \multirow{2}{*}{ Calendar } & Male & $31 \%$ & $6 \%$ & $0 \%$ & 2.83 & .383 & \multirow{2}{*}{.006} \\
\hline & & Female & $44 \%$ & $13 \%$ & $6 \%$ & 2.60 & .675 & \\
\hline \multirow{2}{*}{5} & \multirow{2}{*}{ Camera } & Male & $38 \%$ & $0 \%$ & $0 \%$ & 3.00 & .000 & \multirow{2}{*}{.000} \\
\hline & & Female & $50 \%$ & $6 \%$ & $6 \%$ & 2.70 & .651 & \\
\hline \multirow{2}{*}{6} & \multirow{2}{*}{ Alarm/ Clock } & Male & $38 \%$ & $0 \%$ & $0 \%$ & 3.00 & .000 & \multirow{2}{*}{.003} \\
\hline & & Female & $56 \%$ & $0 \%$ & $6 \%$ & 2.80 & .610 & \\
\hline \multirow{2}{*}{7} & \multirow{2}{*}{ Listening to Sound } & Male & $25 \%$ & $12 \%$ & $0 \%$ & 2.67 & .485 & \multirow{2}{*}{.647} \\
\hline & & Female & $44 \%$ & $19 \%$ & $0 \%$ & 2.70 & .466 & \\
\hline \multirow{2}{*}{8} & \multirow{2}{*}{ Browsing the Web } & Male & $38 \%$ & $0 \%$ & $0 \%$ & 3.00 & .000 & \multirow{2}{*}{.000} \\
\hline & & Female & $44 \%$ & $18 \%$ & $0 \%$ & 2.70 & .466 & \\
\hline \multirow{2}{*}{9} & \multirow{2}{*}{ Games } & Male & $13 \%$ & $25 \%$ & $0 \%$ & 2.33 & .485 & \multirow{2}{*}{.157} \\
\hline & & Female & $25 \%$ & $31 \%$ & $6 \%$ & 2.30 & .651 & \\
\hline \multirow{2}{*}{10} & \multirow{2}{*}{ Sending Email } & Male & $38 \%$ & $0 \%$ & $0 \%$ & 3.00 & .000 & \multirow{2}{*}{.000} \\
\hline & & Female & $50 \%$ & $6 \%$ & $6 \%$ & 2.70 & .651 & \\
\hline & & Male & $38 \%$ & $0 \%$ & $0 \%$ & 3.00 & .000 & \\
\hline 11 & Maps & Female & $31 \%$ & $25 \%$ & $6 \%$ & 2.40 & .675 & .000 \\
\hline 12 & Photo and Video & Male & $31 \%$ & $6 \%$ & $0 \%$ & 2.83 & .383 & \\
\hline 12 & Album & Female & $44 \%$ & $19 \%$ & $0 \%$ & 2.70 & .466 & .031 \\
\hline & & Male & $38 \%$ & $0 \%$ & $0 \%$ & 3.00 & .000 & 000 \\
\hline 13 & Social Networking & Female & $50 \%$ & $12 \%$ & $0 \%$ & 2.80 & .407 & .000 \\
\hline 14 & $0-$ & Male & $38 \%$ & $0 \%$ & $0 \%$ & 3.00 & .000 & 000 \\
\hline 14 & e- & Female & $49 \%$ & $13 \%$ & $0 \%$ & 2.80 & .407 & .000 \\
\hline
\end{tabular}

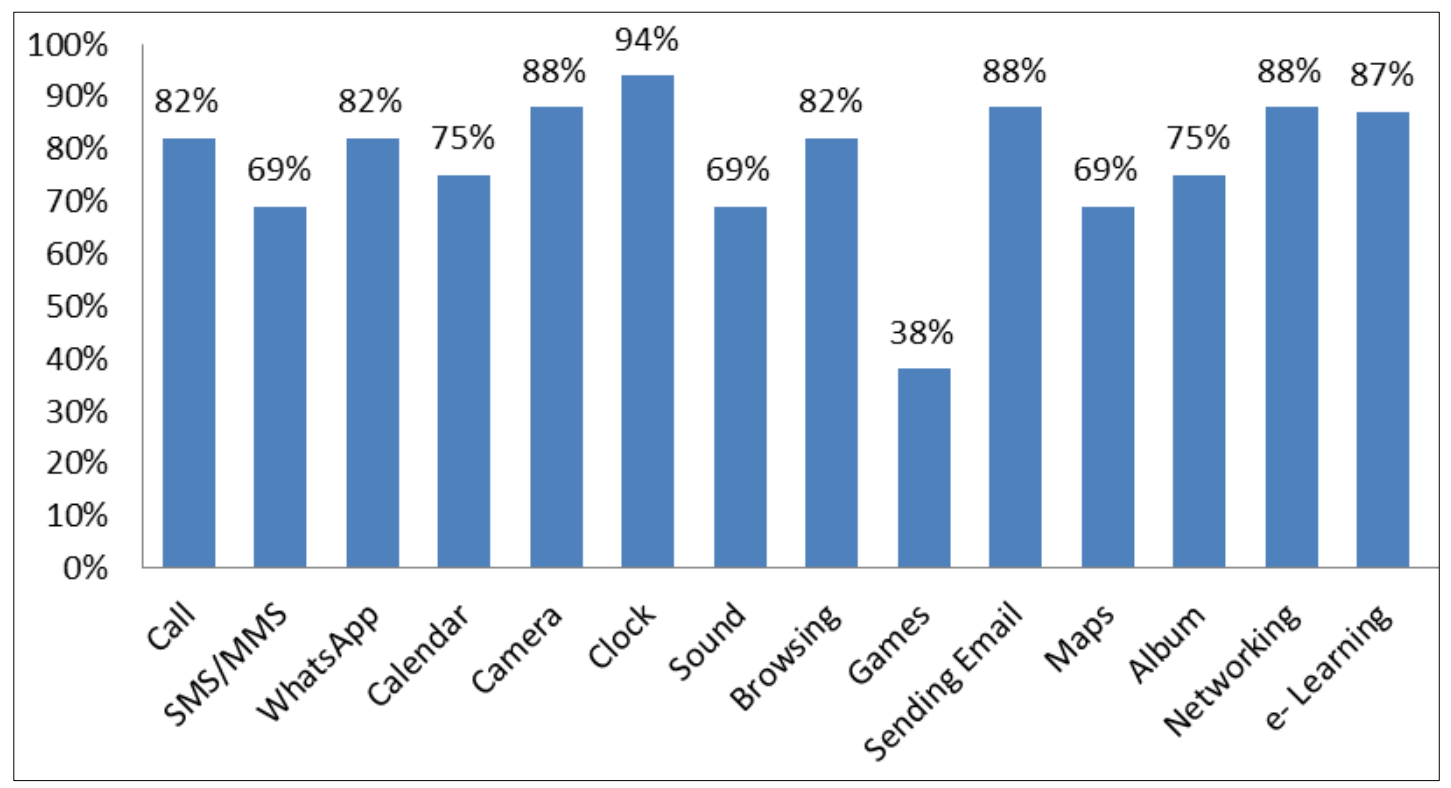

Figure 1: Instructors' Use of Mobile Functions and Applications 


\subsection{Frequent Use of Social Media Applications}

Table (3) and Figure (2) illustrate instructors' frequent use of social media applications such as: Twitter, Instagram, Facebook, YouTube, Snapchat, and LinkedIn. Social media applications offer opportunities to enrich instructors' collaboration, interactivity, and advance instructors' participations and engagements with students [21]. Table (3) shows instructors' use of social media applications. It is interesting to find that Snap Chat is always used by the instructors (38.0\%); Twitter (32\%), Instagram (30.0\%), YouTube $(25.0 \%)$. On the other hand, instructors did not show much interests in LinkedIn, in which only (6.0\%) always use it, while only $(13.0 \%)$ of the instructors always use Facebook.

In addition, the results presented in Table (3) shows that there are no significant differences between male and female instructors in using social media applications. Additionally, "Instagram", "Snap Chat", and "Twitter" are more used by female instructors whereas "Linked In" are mostly used by male instructors. We also found that "Facebook" and "LinkedIn" are the least used by male and female instructors. This finding helps to identify which social media application can be adapted when implementing the new mobile applications for students and instructors in the college.

Table (3): Instructors' Frequent Use of Social Media Applications

\begin{tabular}{|c|c|c|c|c|c|c|c|c|c|}
\hline & $\begin{array}{c}\text { Frequent use of } \\
\text { Social media }\end{array}$ & Gender & Always & Sometimes & Seldom & $\begin{array}{c}\text { I don't } \\
\text { use it }\end{array}$ & Mean & SD & Sig \\
\hline \multirow[b]{2}{*}{1.} & \multirow{2}{*}{ Instagram } & Male & $5 \%$ & $7 \%$ & $19 \%$ & $6 \%$ & 2.33 & .970 & \multirow[b]{2}{*}{.380} \\
\hline & & Female & $25 \%$ & $19 \%$ & $6 \%$ & $13 \%$ & 2.90 & 1.155 & \\
\hline \multirow{2}{*}{2.} & \multirow{2}{*}{ YouTube } & Male & $13 \%$ & $18 \%$ & $6 \%$ & $0 \%$ & 3.17 & .707 & \multirow{2}{*}{.205} \\
\hline & & Female & $12 \%$ & $20 \%$ & $31 \%$ & $0 \%$ & 2.70 & .794 & \\
\hline \multirow{2}{*}{3.} & \multirow{2}{*}{ Snap Chat } & Male & $5 \%$ & $7 \%$ & $13 \%$ & $19 \%$ & 1.67 & 767 & \multirow{2}{*}{.243} \\
\hline & & Female & $33 \%$ & $12 \%$ & $5 \%$ & $6 \%$ & 3.30 & 1.022 & \\
\hline \multirow[b]{2}{*}{4.} & \multirow[b]{2}{*}{ Twitter } & Male & $13 \%$ & $19 \%$ & $0 \%$ & $6 \%$ & 3.00 & 1.029 & \multirow[b]{2}{*}{.353} \\
\hline & & Female & $19 \%$ & $18 \%$ & $19 \%$ & $6 \%$ & 2.80 & .997 & \\
\hline \multirow[b]{2}{*}{5.} & \multirow[b]{2}{*}{ Facebook } & Male & $7 \%$ & $5 \%$ & $25 \%$ & $0 \%$ & 2.50 & .786 & \multirow[b]{2}{*}{388} \\
\hline & & Female & $6 \%$ & $7 \%$ & $19 \%$ & $31 \%$ & 1.80 & .997 & \\
\hline \multirow{2}{*}{6.} & \multirow{2}{*}{ LinkedIn } & Male & $5 \%$ & $0 \%$ & $19 \%$ & $13 \%$ & 2.00 & 1.029 & \multirow{2}{*}{139} \\
\hline & & Female & $1 \%$ & $25 \%$ & $6 \%$ & $31 \%$ & 1.90 & .960 & \\
\hline
\end{tabular}

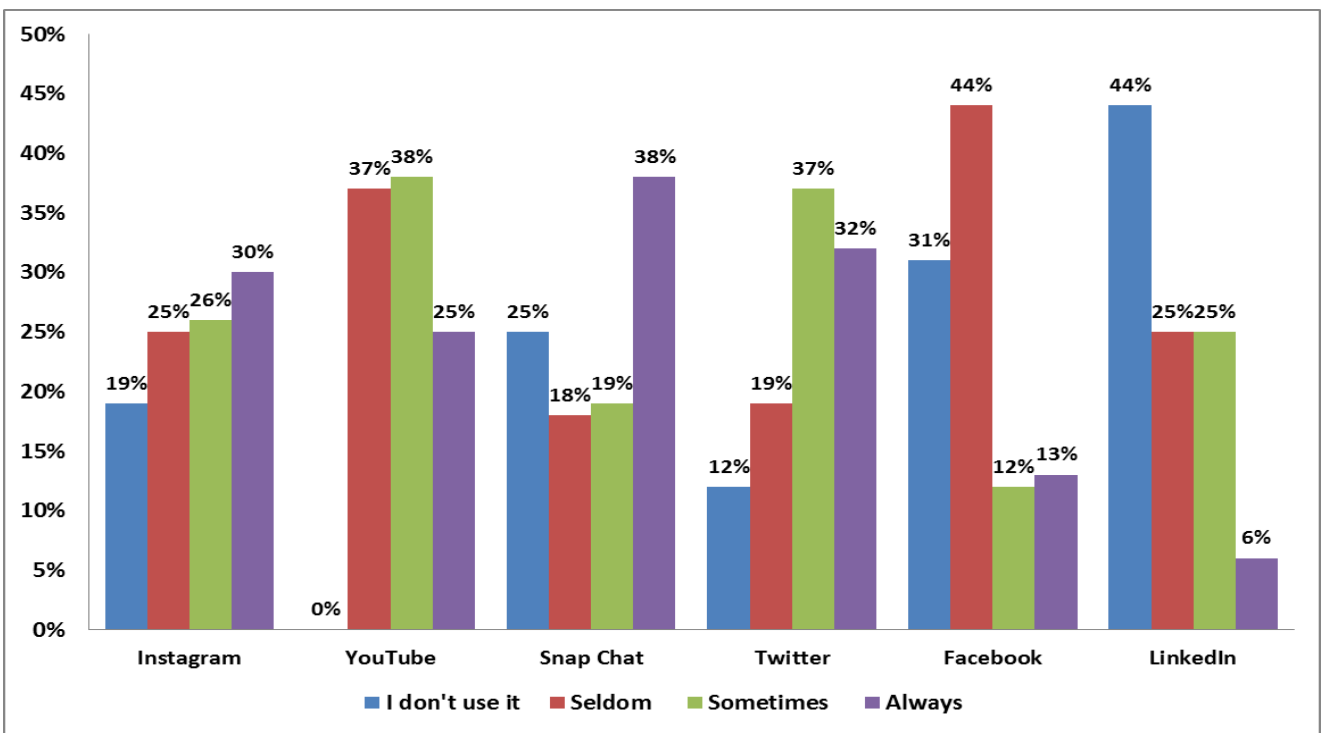

Figure (2): Instructors' Frequent Use of Social Media Applications

\section{CONCLUSION AND FUTURE DIRECTIONS}

The mobile technology has made knowledge easily accessible to those who request it, provide a new generation of people with means of communication and activities, and create opportunities for interaction and collaboration, eliminating barriers among academicians on and off the campus. Higher Education Institutions are in the first rank to know and to make easier the integration of technologies of next generation.

A survey based methodology was used to collect results obtained from $48 \mathrm{HE}$ instructors in the College of Business Studies (CBS) in Kuwait. This study initially aimed to investigate the extent of CBS instructors' usage and preferred functions of mobile devices and applications. Descriptive statistics, t-tests, Mean, and SD were performed. Results indicated instructors' frequent use of mobile functions and applications such as: WhatsApp, photo and video albums, and cameras to engage in content, administrative, management, and entertainment purposes. The analysis of instructors' responses revealed that the instructors welcome the use mobile phones for on and off campus activities. The aim of this study is to understand instructors' habits of the use of mobile capabilities and functions, as well as a common use of social media applications. The finding indicated instructors' frequent use of most of mobile functions, as well as the frequent use of social 
media applications such as twitter, YouTube, Instagram, and Snap Chat. This will guide the developers of mobile applications for CBS, and help them help to effectively utilize mobile capabilities, functions, and applications.

The topics presented here require additional research. Since the survey was limited to one HE college, the outcomes might not be appropriate to other HE institutions from other countries due to cultural differences. Therefore, future research should consider larger sample size from different HE institutions. In addition, more studies need to be carried out using other methodology such as interviews, and focus group.

\section{REFERENCES}

[1] Al-Hunaiyyan, S. Al-Sharhan and R. Alhajri, "A New Mobile Learning Model in the Context of the Smart Classrooms Environment: A Holistic Approach.," International Journal of Interactive Mobile Technologies (iJIM). Vol.11_No.3(2017), pp. 39-56, 2017.

[2] P. Berking, M. Birtwhistle, S. Gallagher and J. Haag, "Mobile Learning Survey Report," Advanced Distributed Learning Initiative, 2013.

[3] A. Nassuora, "Students Acceptance of Mobile Learning for Higher Education in Saudi Arabia," International Journal of Learning Management Systems, vol. 1, no. 1, pp. 1-9, 2013.

[4] T. Wilen-Daugenti and A. McKee, "Dual-mode phones: A smart call for higher education, 1-12. www.cisco.com/web/about/ac79/docs/wp/

Dual_Mode_Phones_WP_0808a.pd,”Cisco, 2008.

[5] Santos, O. Bocheco and C. Habak, "A survey of student and instructor perceptions of personal mobile technology usage and policies for the classroom," Education and Information Technologies. July 2017. DOI: 10.1007/s10639-017-9625-y, 2017.

[6] E. W. Baker, S. S. Al-Gahtani and G. S. Hubona, "The effects of gender and age on new technology implementation in a developing country: Testing the theory of planned behavior (TPB)," Information Technology \& People, vol. 20, no. 4, p. 352-375, 2007.

[7] Kuwait Telecommunications Report Q4, from http://www.researchandmarkets.com/reports/3388100/kuw ait-telecommunications-report-q4-2015, Kuwait, 2015.

[8] A. Lenhart, "Cell phones and American adults.," Pew Research Center, Accessed 10 August 2017. Retrieved from http://www.pewinternet.org/2010/09/02/cell-phonesand-american-adults/, 2010.

[9] Synovate, "Global mobile phone survey shows the mobile is a 'remote control' for life,," Synovate survey. Accessed 18 August 2017. Retrieved from https://www.webwire.com/ViewPressRel.asp?aId=103030, 2009 .

[10] S. Almutairy, T. Davies and W. Dimitriadi, "The Readiness of Applying M-Learning among Saudi Arabian Students at Higher Education," International Journal of Interactive Mobile Technologies iJIM, vol. 9, no. 3, pp. 33-36, 2015.
[11] G. Kennedy, B. Dalgarno, S. Bennett, T. Judd and R. Chang, "Immigrants and natives: investigating differences between staff and students' use of technology," in Proceeding of the 25th annual conference of the Australasian Society for Computers in Tertiary Education (ASCILITE), Deakin University, Melbourne, Australia, 2008.

[12] G. Kennedy, S. Judd, A. Churchward and K. Gary, "First year students' experiences with technology: Are they really digital natives?," Australasian Journal of Educational Technology, 24: , pp. 108-122, 2008.

[13] M. Bayless, T. Clipson and S. Wilson, "Faculty Perceptions and Policies of Students' Use of Personal Technology in the Classroom," Steven Austin State University. Faculty Publications.Paper 32 Retrived from: http://scholarworks.sfasu.edu/businesscom_facultypubs/3, Texas, 2013.

[14] A. Forkosh-Baruch, and H. eishar-Tal, "Proactive, preventive or indifference? Reaction modes of faculty towards use of personal mobile devices in courses," International Journal of Mobile and Blended Learning, 8(2), doi:10.4018/IJMBL.20160401, p. 72-84, 2016.

[15] M. Abbad, D. Morris and C. de Nahlik, "Looking under the Bonnet: Factors Affecting Student Adoption of ELearning Systems in Jordan," International Review of Research in Open and Distance Learning, vol. 10, pp. 1020, 2009.

[16] O'bannon and K. Thomas, "Teacher perceptions of using mobile phones in the classroom: Age matters!," Computers \& Education, 74. Retrieved from: http://scholarworks.sfasu.edu/businesscom_facultypubs/32 /, p. 15-25, 2014.

[17] F. N. Al-Fahad, "Students' attitudes and perceptions towards the effectiveness of mobile learning in King Saud University, Saudi Arabia," The Turkish Online Journal of Educational Technology, vol. 8, no. 2, pp. 111-119, 2009.

[18] A. Kafyulilo, “Access, use and perceptions of teachers and students towards mobile phones as a tool for teaching and learning in Tanzania," Journal Education and Information Technologies. Volume 19 Issue 1, March 2014, pp. 115127, 2014.

[19] Elliot and W. Woodward, Statistical Analysis Quick Reference Guidebook: With SPSS Examples. First Edition, Thousand Oaks, California: Sage Publications, 2007.

[20] Al-Hunaiyyan, R. Alhajri and S. Al-Sharhan, " Perceptions and challenges of mobile learning in Kuwait," AlHunaiyyan, A. Alhajri, R. Al-Sharhan, S. (2016). Journal of King Saud University - Computer and Information Sciences http://dx.doi.org/10.1016/j.jksuci.2016.12.001, 2016.

[21] K. Alhazmi and A. A. Rahman, "Facebook in Higher Education: Students' Use and Perceptions," AISS: Advances in Information Sciences and Service Sciences, vol. 5 , pp. $32-41,2013$. 